\title{
Affective Engagement with Research Evidence about Young People's Sex Education in Kenya
}

\author{
Pauline Oosterhoff ${ }^{1}$, Kelly Shephard ${ }^{1}$, Arno Peeters², Emmy Igonya ${ }^{3}$, Iris Honderdos ${ }^{4}$ \\ ${ }^{1}$ Institute of Development Studies (IDS), Brighton, UK \\ ${ }^{2}$ Tape TV Productions, Utrecht, the Netherlands \\ ${ }^{3}$ Independent Consultant, Utrecht, the Netherlands \\ ${ }^{4}$ Art on Location, Utrecht, the Netherlands \\ Email: P.Oosterhoff@ids.ac.uk, K.Shephard@ids.ac.uk, info@tapetv.nl, \\ igonyae@gmail.com, iris@artonlocation.nl
}

Received 9 June 2016; accepted 18 July 2016; published 21 July 2016

Copyright (C) 2016 by authors and Scientific Research Publishing Inc.

This work is licensed under the Creative Commons Attribution International License (CC BY).

http://creativecommons.org/licenses/by/4.0/

(c) (i) Open Access

\section{Abstract}

Sex and relationships have a big impact on young people's lives. For most young people in the world getting information about sexual pleasure, apart from pornography, can be difficult. And it's even harder if you live in parts of the world where you often aren't able to decide who to date or marry, or how many children you want to have. For this reason online information on sexuality is hugely popular. Research suggests that young people are arriving at sex education sites mostly through campaigns on social media. As not all young people are using these sites it is essential to find creative ways to engage with them in a way that strengthens and builds on existing online sex education. Our recent study used affective engagement as part of a multi-layered and multi-method participatory action research process on online sex education for young Kenyans online. We worked with a group of students from the Sauti music academy, to explore the meaning and relevance of themes that emerged from analysis of online behaviour on the Love Matters sex education platform and off-line research on gender roles and sexuality by young people. Young musicians wrote songs based on the research analysis and recorded these on YouTube. We found that the issues raised by young people using online platforms were also relevant to Kenyan offline non-users. Interpersonal exchange between the young people directly involved in the study, the sexual health experts and international creative team were key to stimulating critical reflection on meanings of sex and love, and creativity in the production of the 15 original songs that were produced during the project. The musicians involved said they had learned how to communicate effectively about sexuality, expectations and affection. Participants also learned how to use their own experiences to connect with people, and most said they realized their responsibility and potential as artists to make progressive social change. Learning on reaching audiences was one of the main unintended benefits for the artists of this project. 


\section{Keywords}

\section{Sex Education, Music, Participation, Young People, Action Research}

\section{Introduction}

Sex and relationships are an important part of young Kenyan people’s lives. Unmarried Kenyan teenagers are sexually active but are excluded from sexual health services. The government considers investments in sexual and reproductive health a national development priority, due to unwanted teenage pregnancies; unsafe abortions (APHRC et al., 2013; MOH, 2012); high maternal mortality rates (Kenya National Bureau of Statistics, 2015); and high HIV prevalence among young men and women of age range15 to 24 (NASCOP, 2009, 2013). Whilst HIV and AIDS education has been part of the curriculum in Kenya since 2003, comprehensive sex education is not available in Kenyan educational institutions. The HIV curriculum stresses abstinence until marriage, and condom use for those who are sexually active, but this has proven to be ineffective in reducing pregnancy or sexually transmitted infections (STIs) (Duflo, Dupas, \& Kremer, 2015). This article examines the opportunities and challenges of affective engagement with research evidence in a collaborative action research project of Kenyan, Dutch and English researchers, musicians and sex educators on sexuality and online sex education for young people. We aimed to engage different and new audiences with research results related to online sex education for young Kenyans.

To improve sexual and reproductive health young people need to be able to make informed choices about sex and relationships. Choice can only happen if they have options, which requires that young people have information. In Kenya sex education in educational institutions, particularly primary and secondary schools, has been highly contested by sexual conservatives including religious groups. Traditional sex education structures have been weaken by social changes including the rise of new evangelical and fundamentalist religious groups. Because it is hard to get good information in real life, online information on sexuality is popular among young people. Kenya has a high internet penetration of $42 \%{ }^{1}$ with $72 \%$ having access to mobile phones ${ }^{2}$. Pornography is easily accessible through the web, mobile phones and social media platforms. Online sex education platforms can help young people to find the facts they need. Love Matters is an international project of Radio Nederland Wereldomroep (RNW), an international non-governmental organization (INGO) that hosts a series of online platforms in different countries. It is committed to reaching young people and subverting sexual and gender stereotypes. Love Matters Kenya uses a pleasure positive approach to delivering digital sex education via their online Sexual and Reproductive Health (SRH) platform aimed at young people between 18 and 30 living in Kenya. Many sex education programs are not able to acknowledge that young people have sex because it feels good, and rather focus on the risk of pregnancy and STIs. Love Matters provides information about sex education including disease prevention and family planning but they also focus on the realities of sexual pleasure and relationships.

Although sex education websites do reach large audiences there are still many young people who are not reached. The Nairobi-based Love Matters website has generated 5.5 million sessions in 2011-2015. But not all young people can easily access online sex education platforms. The mobile-friendly version of the website means that in theory people can access information wherever and whenever they like, but the reality is that they may have to share this phone with somebody else to share costs, or that their parents pay the phone bill and may want to check what it is used for. Most Kenyan users reach the Love Matters website through social media, which is mostly the result of weekly campaigns (Müller, Oosterhoff, \& Chackalackal, 2017). The second largest group reaches it through site via profit-oriented websites, many of which are porn sites (Müller, Oosterhoff, \& Chackalackal, 2017).

Health communications experts have expressed repeated concerns about "magic bullet" thinking in information and education campaigns for progressive social change. While information is key to being able to make choices it is important to acknowledge that information alone is unlikely to change sexual behaviors (Gallanta \&

\footnotetext{
${ }^{1}$ www.internetworldstats.com/stats.htm

${ }^{2}$ http://data.worldbank.org/indicator/IT.CEL.SETS.P2
} 
Maticka-Tyndaleb, 2004). Online information sharing can result in individual and collective action when on and off-line social networks are affectively linked as part of the research design (Hoang \& Oosterhoff, 2016; Oosterhoff, Hoang, \& Quach, 2014). But access to high quality information on sexuality does not necessarily mean that young people can and will act upon this. Information needs to be internalized to make sense to people in their own individual situation, which requires active critical reflection. The facilitation of critical reflection and learning among both the researcher and the "subjects" for action is key in action research. The research and learning are as important as the actions for improving conditions and practices during an iterative process with multiple stakeholders (McNiff \& Whitehead, 2005; Meyer, 2000). And the ability of individuals to take action based on information on sexuality, relationship and sexual health rights is structured by the context. In Nairobi young women and girls face many difficulties in protecting themselves from sexual violence, unwanted pregnancies and accessing SRH services (Oosterhoff \& Igonya, 2015). Inequalities in accessing available SRH services reflect well known structural health and income inequities within the capital (Gulis, Mulumba, Juma, \& Kakosova, 2004). In addition to structural factors such as a functioning health system one needs to also look at social and cultural factors to change social norms and sexual behavior among young people (Wight, Plummer, \& Ross, 2012). Culture informs norms, values and practices with regards to gender and sexual and reproductive health such as Female Genital Mutilation (FGM), early marriage, maternal health and socially sanctioned and illicit sex.

Popular culture — especially music — can be an effective way to reach young people. Undeniably, music and musicians are important in many young people's lives. NGO and researchers have argued that music has great social transformative powers, which can for example, heal and give hope to Africa in a time of HIV (Barz \& Cohen, 2011). However being able to reach young people does not mean that they will adjust their behavior in accordance with the explicit or implicit messages in the music.

Research on HIV and concurrent relationships for example showed the importance of consistent, culturally specific and actionable messages communicated through multiple and credible channels-including interpersonal channels, such as peer educators. Research on effective peer education has showed the importance of building the reflective and critical thinking of these peer educators first (Campbella \& MacPhailb, 2002). Just because people-musicians or otherwise - are the same age does not mean that they can communicate effectively with peers on sexuality in a way that helps them to reflect on their behavior.

Cultural critics and psychologists have highlighted the importance of recognizing agency of audiences in interpreting music, the multiple aims of musical producers, and recognizing the diversity in musical (sub) cultures. Hip hop music videos can contest or confirm traditional views about gender and sexual relationships (Ward, Hansbrough, \& Walker, 2005). The effects of sexual music videos on reinforcing or challenging stereotypical sexual beliefs depends on the specific type of music video, the viewers' gender as well as viewers' affective engagement (Oosten, Jochen, \& Valkenburg, 2015).

Affective engagement is a person-centered conceptual approach that focuses on the role of emotions and affection for understanding rational thoughts, preferences, and choices. It shapes attachment and belonging in environments where everything is in a state of flux (Barker, 2014). Affective engagement is important to understand artistic and musical preferences and choices (Massumi, 2002, 2007, 2008; Oosten, Jochen, \& Valkenburg, 2015). Young people need to feel affective engagement with a certain musician or style in order to accept their messages. In many countries people lost faith in traditional global and national political institutions and authorities to provide for their needs. Celebrity activism therefore needs to be placed within a context of global political affective disengagement (Cooper 2008; Tsaliki, Frangonikolopoulos, \& Huliaris, 2011). However, who is seen as acceptable by a young person might not be what an adult working with an NGO has in mind.

Young Kenyans find themselves in a country with a neoliberal economic growth model that has had high economic growth rates but also growing inequalities and insecurity. $71 \%$ of the urban population lives in slums with very limited employment and formal political participation opportunities, creating new spaces for other forms of leadership. High-profile Kenyan runners were found to be very effective in mobilizing resources, pursuing political opportunities and devising a collective action frame for reconciliation in the post-election conflicts in Kenya in $2008^{3}$. The athletes were positioned in the impacted communities. They could engage effec-

${ }^{3}$ Brian Wilson, Nicolien Van Luijk, Michael K Boit, 2015 When celebrity athletes are "social movement entrepreneurs”: A study of the role of elite runners in run-for-peace events in post-conflict Kenya in 2008 International Review for the Sociology of Sport vol. 50 no. 8 929-957. 
tively and affectively, because they were seen as credible, positive and accessible to urban disenchanted youth. Although they are very different from these athletes effective sex educators are very familiar with the need for open-minded, accessible non-judgmental and positive approaches.

We used affective engagement in our collaborative action research as a strategy to engage with different and new audiences on research findings about sexuality and relationships. We conducted on- and off-line research on gender and sexuality and developed a partnership with the Sauti Academy in Kenya (part of record label Penya in Nairobi) and two Dutch artists (a composer and music producer, and a visual multi-media artist). The creative team supported a group of students from the music academy, to explore the meaning and relevance of themes that emerged from analysis of online behavior on the Love Matters sex education platform and off-line research on gender roles and sexuality by young people. Participation was open to music students ranging from 18 to 30 years old studying at the Academy in Nairobi. The musicians wrote songs that were inspired by research findings and performed these for an online competition on YouTube which was promoted through the Love Matters website and associated social media. Entries were critiqued by a panel of judges that included experts and music and media professionals. Meanwhile global audiences voted via Youtube for a People's Choice Award. The winners were signed by a major Kenyan record label and all of the participants were invited to perform for a live audience. This performance mixed theatre with music. This article examines if and how our affective engagement approach worked and for whom.

\section{Methods}

IDS researchers involved in the study conducted a literature review of the formal and informal literature on sexuality, gender, pop music and sexual and reproductive health. Drawing from information-seeking behavior collected by Love Matters as part of its standard quality control we analyzed online behavior of 1,806,873 Users in the period between 1 June 2013 and 31 August 2015. We looked at the Page Views, Pages/Session Average, Session Duration and Bounce Rate.

To understand if and what the added benefit is of a pleasure-based approach Love Matters uses a system to classify user behavior in a session. Web searches under the headings of sex, love and relationships and marriages are classified as pleasure. Sessions are classified as sex education when users go to the site sections that are marked "his body" or "her body", "disease prevention" (which has subheadings of safer sex), "sexually transmitted diseases" and "family planning" (which has subheadings of birth control and pregnancy).

We combined these standardized quantitative data with more qualitative data on questions and comments for Love Matters experts on social media. Based on our analysis of this information we developed questions around gender, masculinity and sexuality for five focus group discussions with young men and women in Nairobi and Mombasa. The Kenyan interviewers all had extensive and very detailed experience of talking about sexuality with young Kenyans in urban settings allowing them to answer many questions that emerged during these often very lively discussions.

We also tried to understand young people's music preferences by conducting online research, followed by individual interviews with people working in the commercial music industry in Kenya and people with experience with collaborations of Kenyan musicians and the NGO sector. The findings were translated into focus group discussion questions about music and artists.

Meanwhile, observations of off-line environments in slum and entertainment areas in Nairobi and Mombasa were conducted and students were interviewed at the end of the project to assess what they had learned that was valuable for them as musicians and artists as well as at a personal level.

Last but not least, the artists, researchers, and the Love Matters project staff spent a lot of time discussing and reaching a common understanding of our distinct responsibilities and roles. The process of the collaboration from the artist's perspectives has been documented in various interlinked blogs (Peeters, 2016a, 2016b). The purpose of the blog from a researcher's perspective was to help external audiences understand the detailed work that goes into creating affective engagement with research. Processes and vocabularies that are familiar to NGO and researchers such as TOR ("Terms of Reference”), FDG's ("Focus Group Discussions") and the comms plan ("communication strategies") are not self-explanatory to outsiders including the artists. Three months prior to the arrival of the artists in November the project team had regular meetings (mostly on Skype) and exchanged over 146 emails with the artists alone to secure the details of the work plan and budget. This article also draws upon this communication. 


\section{Findings}

User behavior in most countries where Love Matters operates shows a clear preference for search headings and subheadings on sex, love and relationships and marriages that would be classified under pleasure. Kenya however had a high number of web page views falling within the category of sex education. A closer look revealed that this was largely due to searches for "penis"-including but not limited to penis size. Questions and comments for Love matters experts on social media suggested that young Kenyans are insecure; one of the most frequently asked questions on the Love Matters site is the “Am I normal” question? Or "Is my penis size, vagina size, or feelings” normal? (Chakkalackal, 2015). Other questions suggested that young people do not know what to expect from themselves and their partners in a relationship. We therefore decided to explore young people's perception of sexuality and insecurity in more depth through focus group discussions, and asked young people why they thought the web pages on penis shapes and sizes are so popular and why Love Matters often get questions from guys who worry about whether their size will affect their ability to make love. We also explored other questions that came up from the online interactions such as: What does sexual pleasure mean? Who is responsible for having pleasurable sex in a relationship? And what does it mean to be a young man or woman in a relationship? Male and female respondents thought that the reason why guys worry about the size of the penis is not so much a physical issue but one relating to their insecurity about their masculinity, as one young man explained:

"There are three things that are important in masculinity and sex: Money, swag, and sexual performance. Let's talk facts, money and sexual performance are most important.” (Male respondent, FGD, Mombasa).

All men believed that women place a high importance on money and a man with money who cannot sexually satisfy women or is infertile is at risk of being cheated sexually and financially. Their partners might find another sexual partner who can sexually satisfy her or produce a child and make the infertile man pay for the child or even for sexual services by other men. Many men said the size of a penis is instrumental for giving women pleasure. However some men highlighted that sexual techniques by experienced women can help to make a fit.

"So when the vagina is big then you do not really get the pleasure and that is why women do certain things like using some soaps or lemon to tighten the vagina for the man to feel them and have pleasure." (Male respondent, FGD, Mombasa).

A small penis that requires female expertise however was often seen as emasculating because men consider themselves to be the main person responsible in making sure that sex is pleasurable. When we asked men in a Nairobi focus group: Whose responsibility is your sex life, yours or your sex partner? The response in chorus was: Mine. Some women however did feel their partner had a role in it.

Not a single respondent we spoke with felt they had been prepared for this through sex education. Some had been sexually active since they were 12, without having received any sex education by their parents or school. None of them had heard about Love Matters or looked online for sex education outside of porn. One respondent was "in primary school, in class seven when I was caught red handed in the act by my mother. I was already sexually active and I used to have sex with different girls. I did not know when my mother was coming back to the house. Then when we just got into sex, my mother arrived and caught us. I was beaten thoroughly.” (Young male student, FDG, Nairobi). Several years passed and it was only when his mother found him in bed again with a girl from the church choir that she shouted at him that he could make girls pregnant, something he had not realized before. This combination of pressure, insecurity and ignorance explains why the word 'how' shows up so often in online queries by men.

Both women and men consider being responsible and having money essential in having access to sex and being an attractive man.

"Masculinity is about working and providing." (Young man, FGD Mombasa).

"Masculinity is responsibilities; you have to be responsible or take responsibilities, especially providing for your family.” (Young man, FGD Mombasa).

Given the lack of income generating options for many of these young men compared with the expectations to demonstrate that they can take care of themselves, their wife, their parents, siblings and girlfriends it is not surprising that many men felt insecure and resentful.

“We do not want responsibilities.” (Young male student, FDG, Nairobi). Several young men said that girls 
hurt their feelings by telling them they "cannot eat love" and that "love does not buy me clothes".

Girls in contrast felt that men did not take their responsibilities—financial and sexual-seriously. While girls were more explicit about both partners being responsible for having pleasurable sex they highlighted that it is girls who are left pregnant when a couple has unprotected sex.

"In Kenya unless you had sex with a rich man you can take to court, you bear the responsibility of raising the baby alone. Many women have their lives ruined because they got pregnant. While the men went on with their lives, the women drop out of school or college to take care of the children. So it is the women who should be responsible for sex life." (Young female professional, Nairobi).

When an unmarried girl is pregnant her parents have to pay for the upkeep of her and her child. As a consequence girls are likely to drop out of school while their male partner is not affected. Therefore women were vocal about the consequences of unplanned pregnancies.

"You are in trouble when you live with your parents because if you get pregnant you have given them another responsibility. You will be forced to move in with your friends and you know the hospitality of friends is limited. Here in Mombasa, your friends will lead you to sex work." (Young female professional, Mombasa).

What was striking in these interviews was the suspicion between boys and girls of each other's intentions and the lack of open communication about each other's expectations with regards to sex, pleasure and finances. Both men and women had many ideas about each other's sexuality - who should have an orgasm first, whether women should make sounds or be silent, how long pleasurable sex should be—but we did not hear of a single case of couples who spoke directly with each other about their expectations, desires and needs.

Based on these findings we asked the students to compose songs about two major themes.

1. Being responsible. Both boys and girls talk about responsibility. Responsibility can be a duty, a burden, and a desirable characteristic. How does pleasure relate to sexual responsibility?

2. Expectations of sex and relationships. Boys and girls have quite different expectations of sex and relationships but they are not talking openly with each other. There is a lot of suspicion about each other's motives and many young people question whether their thoughts and desires are 'normal'.

\subsection{Evidence-Based Musical Engagement}

Research on peer educators has shown that the development of critical thinking and empowerment are key preconditions for successful collaborations (Campbella \& MacPhailb, 2002). As we were working with young musicians we felt it might be useful to make sure they learned about the different forms of engagement that their peers-that is other musicians-had taken on sexuality, the key issues that young Kenyans face with regards to pleasure and sexuality and creative methods to work with one's own emotional affective experiences to create songs that engage audiences. Therefore we organized a three-day workshop that is described in more detail by the artists (Peeters, 2015a). To help students reflect on engaged art we showed on the first day some video examples of music that effectively addressed a range of issues related to sexuality such as "Tyrone", the "answer" to it by Erykah Badu; "Simone" by comedian Tracey Morgan and Lady Gaga's "Til it Happens to You". On the second day a sex educator from Love Matters came in and students could ask her everything they had always wanted to know about sex. This was followed by 'free writing' on the subject of sex, responding to the research themes. Writing "free" means writing whatever comes to mind in one flow for 10 minutes, preferably without stopping. At the end of the day some students had written complete lyrics. On the third day students worked together to put these songs onto music with coaching by the director of the academy, a highly respected teacher and talent coach in Kenya. This intense production process was quite emotional at times with students sharing sometimes painful but also funny stories about their sexual adventures. After the workshop we gave the students two days to complete the songs before recording and publishing them on YouTube. To give each student an equal chance students recorded without a visual backdrop and only live musical support with a camera positioned at the same place using the same lighting. The themes of the 15 recorded songs on Love Matters YouTube channel covered everything from how society deals with the internet and the rise of a digital generation, and rape, to individual longing to have sex after a dry spell.

The election of the People's Choice Award was based on the number of views and likes on YouTube and Fa- 
cebook. For the Jury's award an international panel of researchers, media and music experts judged the songs on a range of criteria including content, creativity (use of relevant references to illustrate the issues), relevance and awareness of the youth audience in Kenya, originality and quality of sound.

While the public and the jury judged the individual work, the international creative team worked with the students to create a live multi-media performance in a modern art centre in Nairobi. The performance guided the audience through a narrative told through sketches and songs based on the research and the workshops. The audience were given a tour as the narrative unfolded on three stages with artists performing in front of screens with video-art and multi-media creations. For example, to engage with sexual performance anxiety and uber-masculinity the artists created a fake Facebook page of a male character with a love for women, fast cars and glamor, a reference to masculinity in rap music. One of the rappers performed a humorous but graphic song about confusion on sexual performance anxiety, which led into a song about a woman who was not interested in a man's love but in his money. Each song was performed in a different multi-layered multi-media context.

\subsection{Taking Stock of Affective Engagement}

Central to the project's communications strategy was the expectation that each student would market their own song to get votes. Most, but not all, of the students owned smartphones, but few used e-mail or Facebook instead relying on WhatsApp or SMS. The social marketing expert from Love Matters provided an informal "how to" crash course on social media to help students share their songs. After a slow start students actively promoted their work. The song attaining the highest number of Youtube views (over 9000 views in two weeks) was by TheAfrican, a woman who lived in a slum area. She achieved this despite having no smartphone of her own and no experience at all with social media. She managed to achieve this number of views by using her face-to-face social skills and charm, mobilizing strangers with smartphones on Nairobi buses to vote for her, and asking her brothers to go into internet cafes to ask people to vote. The winner Helena was-we learned later-not very active on Facebook either, but her song about a girl she knew who was raped struck a chord with strangers on the internet and over 30,000 people voted for her on the Love Matters Facebook site. The jury award winner Omari didn't have so many votes but his song about the lack of protection for young Kenyans to violence on the internet was a clear favorite with the judges.

The live performance was wellattended but not without its challenges. The students arrived too late to do a proper run through. The main sound engineer left midday, taking half the light and sound equipment with him, and leaving a sole, unprepared technician to do all the work with what was left. In spite of the lack of preparation the students performed well but the sound quality was still suboptimal. The venue provided some extra loudspeakers, but they were broken since they had been left in the rain at an earlier concert. Complaining to the company was not useful as the sound engineer never returned to the office and could not be traced. While researchers, NGO members and the creative team took turns cringing about squeaky sounds the audience enjoyed the performance.

The event was widely covered in the international and national press. Written coverage included the Guar$\operatorname{dian}^{4}$ and One World, local coverage in The Star ${ }^{5}$ and Mpasho, meanwhile Ghetto Radio broadcast daily evening shout-outs in the four days prior to the event, with calls to social media action and voting. In the academic sector several blogs focused on the use of action research methods including the IDS Sexuality, Poverty and Law website $^{6}$ whilst on the IDS website we documented the wider contextual challenges ${ }^{7}$.

Individual interviews with students, artists and NGOs as part of the review of this project showed, not surprisingly, that different people had appreciated different things at different times.

Musicians said they had learned at the workshop how to communicate effectively about sexuality, expectations and affection. "This project helped me as an artist and as a person. As a person I learned how to communicate better with my own partner. I learned about the value of communication to work things through. I also learned that I can engage as an individual with audience and use my own feelings to create songs about important topics in Kenya." (Female student).

Participants also learned how to use their own experiences to connect with people, and most said they realized

\footnotetext{
${ }^{4}$ http://www.theguardian.com/global-development/2015/dec/11/love-matters-teaching-young-people-kenya-safe-healthy-sex-life

hhttp://www.the-star.co.ke/news/2015/12/09/love-matters-launches-new-love-sex-and-relationships-show_c1257650

${ }^{6}$ http://spl.ids.ac.uk/blog/love-matters-background

${ }^{7}$ ttp://www.ids.ac.uk/opinion/if-the-pope-wants-to-end-violence-in-africa-he-ll-have-to-talk-about-sex
} 
their responsibility and potential as artists to make progressive social change. "I wanted to be an artist of the people. But I did not know what that meant. I now know what it means to be engaged." (Male student). "I am proud to have created a song about something bad that happened to me and see how much others appreciate this artistic and personal honesty." (Female student).

Our evaluation found that learning how to market themselves and reaching audiences was one of the main unintended benefits for the artists of this project. "I have learned to trust my own talents more. I am from the slums. I have no money. No connections. But I now know I have an audience and I can use social media to connect with them myself." (Male student).

The Love Matters project staff was used to communicating with their audience online. Given that the number of Love Matters webpage views has constantly been rising, and mobile phone and internet usage in Kenya is very high, some staff initially felt no need to go offline. They felt their audience was online. However the research showed that there were potential audiences that were not reached and the value of interpersonal contact in helping individuals reflect on sexuality and relationships. "I was a bit skeptical about this approach. I am used to a more controlled digital environment. But I can now see how we can engage off line with a different audience that we are not reaching through an online entry point." (Staff Love Matters).

For the researchers the competition confirmed the importance and the potential of linking on- and off-line social networks and social mobilization in affective and effective engagement with participatory action research found in other settings (Hoang \& Oosterhoff, 2016).

\section{Conclusions}

Overall we found affective engagement a very successful and joyful approach to action research carried out in collaborative teams with different backgrounds and skills. In this study a team of researchers, international project staff, musicians and multi-media artists worked effectively together on mobilizing audiences based on research evidence. Researchers and international project staff explored if and how some of the behavior online was also relevant to young Kenyans who are not using these services. This allowed us to gain insight into whether the non-use was clearly related to the website content or due to other factors. Although none of the offline respondents knew of the Love Matters site they found the topics relevant, but articulated that many young Kenyans have sex before they are 18 . The site-for legal reasons-is targeted at over 18 year olds.

Affective engagement with both the research topic and socially engaged art was important in inspiring musicians to produce compelling and original songs. This collaboration involved a conscious radical shift of powers away from the researchers. The participating students of the academy were selected by experts in the music industry, exclusively based on talent. The researchers or NGO had no say in their selection, the way they treated the content of the research, or the selection of winning songs. Once we had collected and analyzed our data we trusted that the themes identified were central to the attitudes, the emotional lives and lived experiences on sexuality and relationships of young Kenyans.

The research supported the creative team to discuss emotionally charged and taboo themes in an open fashion. While the creative team was at first hesitant about talking explicitly about sex we could reassure them by pointing out that 5.5 million sessions online on the Love Matters website should be an indication about peoples interest in the topic and sharing findings from sexually explicit focus group discussions. The creative team also learned more about the questions young people have about sexuality from watching the Kenyan researcher and an international sexual health expert interact with the students, speaking in plain language about a wide range of sexuality related topic. This helped them to understand what topics are relevant to students and how they can be discussed.

Although the researchers designed the action research and decided the themes of the competition we allowed others to decide if, how and what they wanted to communicate in terms of the results. The songs were directly related to the research themes but presented in a fresh ways to audiences - such as to random smartphone owners on buses - that researchers usually are not communicating with, and certainly had not thought of before. The production of the installation artworks and the performance were led by the artists and students in consultation with the lead researcher but designed, created and supervised by the artists themselves. These complementary, unique and different roles, highlight the importance of partnership in coproduction of concept, process, products, and knowledge in effective action research. The impact of the research is still growing through these partnerships as the winning musicians release their songs and video clips on the market. One of the students wants to start an NGO to respond to the emotional needs of raped teenagers. 


\section{Acknowledgements}

The project was jointly undertaken by the Institute of Development Studies (IDS), Love Matters, Sauti Academy and Penya.

Many people have contributed their time and efforts to this work. We thank the participants in the focus group discussions, the students and Natalie Lukenaer the director of the Sauti Acedemy for their support. We particularly would like to acknowledge the incredible practical and moral support and valuable comments by Hannah Wallace Bowman at Love Matters as well as all the help provided by the Love Matters staff in Kenya.

This case study was funded by the Dutch government; however, the views expressed do not necessarily reflect the Dutch government's policies.

\section{References}

African Population and Health Research Center (APHRC), Ministry of Health Kenya, Ipas \& Guttmacher Institute (2013). Incidence and Complications of Unsafe Abortion in Kenya: Key Findings of a National Study. Nairobi, Kenya.

Barker, J. (2014). Agustín Fernández Mallo’s Nocilla Project: Seeking Affective Engagement in the World City. Arizona Journal of Hispanic Cultural Studies, 18, 31-52. http://dx.doi.org/10.1353/hcs.2014.0027

Barz, G., \& Cohen, J. M. (2011). The Culture of AIDS in Africa: Hope and Healing Through Music and the Arts. New York: Oxford University Press. http://dx.doi.org/10.1093/acprof:osobl/9780199744473.001.0001

Campbella, C., \& MacPhailb, C. (2002). Peer Education, Gender and the Development of Critical Consciousness: Participatory HIV Prevention by South African Youth. Social Science \& Medicine, 55, 331-345. http://dx.doi.org/10.1016/S0277-9536(01)00289-1

Chakkalackal, M. (2015). Engaging Young People with Pleasure: Positive Sex Education. World Association for Sexual Health Conference, Singapore. http://www.sexualhealthvisual.com/Video_by_Michelle_Chakkalackal_on_Engaging_young_people_with_pleasure_positi ve_sex_education.html

Cooper, A. F. (2008). Beyond One Image Fits All: Bono and the Complexity of Celebrity Diplomacy. Global Governance: A Review of Multilateralism and International Organizations, 14, 265-272.

Duflo, E., Dupas, P., \& Kremer, M. (2015). Education, HIV, and Early Fertility: Experimental Evidence from Kenya. American Economic Review, American Economic Association, 105, 2757-2797.

Gallanta, M., \& Maticka-Tyndaleb, E. (2004). School-Based HIV Prevention Programmes for African Youth. Social Science \& Medicine, 58, 1337-1351. http://dx.doi.org/10.1016/S0277-9536(03)00331-9

Gulis, G., Mulumba, J. A., Juma, O., \& Kakosova, B. (2004). Health Status of People of Slums in Nairobi, Kenya. Environmental Research, 92, 219-227. http://dx.doi.org/10.1016/j.envres.2004.01.016

Hoang, T.-A., \& Oosterhoff, P. (2016). Transgender at Work: Livelihoods for Transgender People in Vietnam. IDS Evidence Report 167, Brighton: IDS.

Kenya National Bureau of Statistics (2015). Kenya Demographic and Health Survey. Kenya Ministry of Health, Nairobi National AIDS Control Council, Kenya Medical Research Institute, National Council for Population and Development. World Bank.

Massumi, B. (2002). Parables for the Virtual: Movement, Affect, Sensation. Durham, NC: Duke University Press. http://dx.doi.org/10.1215/9780822383574

Massumi, B. (2008). The Thinking-Feeling of What Happens. 3 Inflexions 1.1 "How Is Research-Creation?” www.inflexions.org

Massumi, B., Mertens D., Spuybroek, L., Marres, M., \& Hubler, C. (2007). Interact or Die: There Is Drama in the Networks (pp. 70-91). Rotterdam: NAI Publishers.

McNiff, J., \& Whitehead, J. (2005). All You Need to Know about Action Research. London: SAGE.

Meyer, J. (2000). Using Qualitative Methods in Health Related Action Research. The British Medical Journal, 320, $178-181$. http://dx.doi.org/10.1136/bmj.320.7228.178

Ministry of Health Service and Ministry for Public Health and Sanitation (2012). Kenya Health Policy 2012-2030. Kenya: Government of Kenya.

Müller, C., Oosterhoff, P., \& Chakkalackal, M. (2017). Digital Pathways to Sex Education. IDS Bulletin: Sex Education in the Digital Era. (Forthcoming)

National AIDS \& STI Control Programme (NASCOP) (2009). Kenya AIDS Indicator Study 200. Kenya: Ministry of Health.

National AIDS \& STI Control Programme (NASCOP) (2013). The Kenya AIDS Indicator Survey 2012. Kenya: Ministry of Health. 
Oosten van, J. M. F., Jochen, P., \& Valkenburg, P. M. (2015). The Influence of Sexual Music Videos on Adolescents’ Misogynistic Beliefs: The Role of Video Content, Gender, and Affective Engagement. Communication Research, 42, 9861008. http://dx.doi.org/10.1177/0093650214565893

Oosterhoff, P., \& Kageha Igonya, E. (2015). Empowerment of Women and Girls: Constitutional Reforms and Access to HIV Services for Women in Low-Resource Settings in Nairobi, Kenya. IDS Evidence Report No. 137, Brighton: IDS.

Oosterhoff, P., Hoang, T.-A., \& Quach, T. T. (2014). Negotiating Public and Legal Spaces: The Emergence of an LGBT Movement in Vietnam. IDS Evidence Report 74, Brighton: IDS.

Peeters, A. (2016a). \#LoveAwards: Young Kenyans Compete to Produce Songs on Pleasure and Sexuality. http://spl.ids.ac.uk/blog/loveawards-\%E2\%80\%93-young-kenyans-compete-produce-songs-pleasure-and-sexuality

Peeters, A. (2016b). Love Matters Awards: The Journey to the Public Vote. http://spl.ids.ac.uk/blog/love-matters-background

Tsaliki, L., Frangonikolopoulos, C. A., \& Huliaris, A. (2011). Transnational Celebrity Activism in Global Politics: Changing the World? Bristol: Intellect.

Ward, M., Hansbrough, E., \& Walker, E. (2005). Contributions of Music Video Exposure to Black Adolescents' Gender and Sexual Schemas. Journal of Adolescent Research, 20, 143-166. http://dx.doi.org/10.1177/0743558404271135

Wight, D., Plummer, M., \& Ross, D. (2012). The Need to Promote Behaviour Change at the Cultural Level: One Factor Explaining the Limited Impact of the MEMA Kwa Vijana Adolescent Sexual Health Intervention in Rural Tanzania. A Process Evaluation. BMC Public Health, 12, 788.

Wilson, B., Van Luijk, N., \& Boit, M. K. (2015). When Celebrity Athletes Are 'Social Movement Entrepreneurs': A Study of the Role of Elite Runners in Run-for-Peace Events in Post-Conflict Kenya in 2008. International Review for the Sociology of Sport, 50, 929-957. http://dx.doi.org/10.1177/1012690213506005

\section{Submit or recommend next manuscript to SCIRP and we will provide best service for you:}

Accepting pre-submission inquiries through Email, Facebook, LinkedIn, Twitter, etc.

A wide selection of journals (inclusive of 9 subjects, more than 200 journals)

Providing 24-hour high-quality service

User-friendly online submission system

Fair and swift peer-review system

Efficient typesetting and proofreading procedure

Display of the result of downloads and visits, as well as the number of cited articles

Maximum dissemination of your research work

Submit your manuscript at: http://papersubmission.scirp.org/ 